\title{
Subcutaneous Port Site
}

National Cancer Institute

\section{Source}

National Cancer Institute. Subcutaneous Port Site. NCI Thesaurus. Code C147512.

The anatomic site at which a subcutaneous port is implanted under the skin, allowing access to the vascular system or a body cavity. 